\title{
Assessing the regional spatio-temporal pattern of water stress: A case study in Zhangye City of China
}

\author{
Qian Zhang ${ }^{\mathrm{a}, *}$, Bing Liu ${ }^{\mathrm{b}}$, Weige Zhang ${ }^{\mathrm{b}}$, Gui Jin ${ }^{\mathrm{c}}$, Zhaohua Li $^{\mathrm{c}}$ \\ ${ }^{a}$ Center for Chinese Agricultural Policy, Institute of Geographic Sciences and Natural Resources Research, Chinese Academy of Sciences, 11A Datun Road, Chaoyang District, \\ Beijing 100101, China \\ ${ }^{\mathrm{b}}$ School of Geoinformatics, Shandong University of Science and Technology, 579 Qianwangang Road, Qingdao 266590, China \\ ${ }^{\mathrm{c}}$ Faculty of Resources and Environmental Science, Hubei University, 368 Youyi Road, Wuchang District, Wuhan 430062, China
}

\section{A R T I C L E I N F O}

\section{Article history:}

Received 21 October 2014

Accepted 27 October 2014

Available online 6 November 2014

\section{Keywords:}

Water stress

Water Poverty Index

Spatio-temporal pattern

Trajectory

Typology

Water resource management

\begin{abstract}
A B S T R A C T
Water scarcity and stress have attracted increasing attention as water has become increasingly regarded as one of the most critical resources in the world's sustainable development. The Water Poverty Index (WPI), an interdisciplinary but straightforward measure that considers water availability from both the bio-geophysical perspective and the socio-economic perspective of people's capacity to access water, has been successfully applied at national, regional, and local levels around the world. However, the general assessment of water stress at a macro level over only a snapshot limits the understanding of the geographic differences in and dynamics of water stress; this will, in turn, mislead decision-makers and may result in improper water strategies being implemented. In addition, to date, the typologies and trajectories of water stress have been underexplored. To fill this knowledge gap, we examine the spatio-temporal patterns, trajectories, and typologies of water stress using an adapted WPI for six counties in Zhangye City, which lies within an arid region of China, in order to provide policy priorities for each county. The results of our assessment indicate that water stress has become more severe over time (20052011) in most of the counties in Zhangye City. The results also show a distinct spatial variation in water scarcity and stress. Specifically, the results for Shandan county reflect its progressive policies on water access and management, and this county is regarded as engaging in good water governance. In contrast Ganzhou district has faced more severe water pressure and is regarded as practicing poor water governance. Typology results show that each county faces its own particular challenges and opportunities in the context of water scarcity and stress. In addition, the trajectory map reveals that none of the counties has shown substantial improvement in both water access and management, a finding that should draw decision-makers' close attention.
\end{abstract}

(c) 2014 Elsevier Ltd. All rights reserved.

\section{Introduction}

Water scarcity and stress have attracted more attention as a result of water being increasingly regarded as one of the most critically limited resources in the world's sustainable development (Falkenmark and Whdstrand, 1992; Vörösmarty et al., 2000). Water stress is an integrated concept, and should be measured from the perspective of natural water availability and from the socio-economic perspective of people's ability to access water (Feitelson and Chenoweth, 2002; Lawrence et al., 2003; Sullivan and Meigh, 2007). The interdisciplinary approach suggested by this concept, which addresses crosscutting issues in an integrated way,

\footnotetext{
* Corresponding author. Tel.: +8610 6488 8979; fax: +861064856533

E-mail address: zhangq.ccap@igsnrr.ac.cn (Q. Zhang).
}

allows spatio-temporal patterns and trajectories of water scarcity and stress to be measured. The approach is of particular significance for discovering more equitable solutions for water allocation, especially for a water-deficient but rapidly developing city such as Zhangye City within the arid region of northwestern China.

Previous studies have made substantial efforts to generate suitable expressions to represent water scarcity and stress (Alcamo et al., 1997; Deng et al., 2014; Deng and Zhao, 2014; Smakhtin et al., 2004; Sullivan, 2001a,b, 2002), such as the Water Poverty Index (WPI). Condensed indices of water stress are very useful for focusing and simplifying the problem, and are more effective at drawing public attention and more influential in affecting policy-makers' decisions than are long lists of multiple factors or measures. As a result, the indices, rather than precise measures, have assumed considerable political appeal and have become an important water management tool. The WPI considers water availability 
from both the bio-geophysical perspective and the socio-economic perspective of people's ability to access water. The WPI was originally developed as a holistic tool to measure water stress at the household and community levels in the early 2000s (Sullivan, 2001a,b, 2002; Sullivan et al., 2003). Through combining a cluster of data that are both directly and indirectly relevant to water scarcity and stress into a single number, the WPI provides a basis for ranking administrative units in terms of water availability and the effectiveness of water management, and assists both national and local decision-makers to better determine policy priorities for making interventions in the water sector.

However, the spatial variation in water availability and in access to water resources is distinct and particularly important, even for adjacent locations within the same watershed. The general assessment of water stress at a macro level over only a snapshot is likely to limit the understanding of geographic differences in water scarcity and stress, which may in turn mislead decisionmakers to adopt improper strategies. Therefore, water stress assessment and water resource governance at a variety of scales become increasingly imperative (Perveen and James, 2009). Furthermore, time series water stress analysis based on changes in socio-economic and bio-geophysical factors can provide richer information for making decisions on water usage and management than can snapshot descriptions. To date, the trajectories and typologies of water stress have been underexplored, and to our knowledge the present study is the first attempt to illustrate the trajectories of water stress at the local level.

The objective of this study using the interdisciplinary approach outlined above is to explore the spatio-temporal pattern, trajectories, and typologies of water stress for counties in Zhangye City, which is located in an arid region of China, using an adapted WPI. We follow the principal of generating the WPI and only adapt the indicators (variables) to calculate the WPI according to the specific characteristics of this study area. In this paper, we examine the trends and patterns of water stress, investigate the underlying factors that affect water stress, and consequently provide policy priorities for the specific counties within the study area. The rest of the paper is structured as follows. First, we briefly describe the study area (Section 2). Next, we present the main datasets and methodology used in this study (Section 3). We then present and discuss the results and identify future research directions in detail (Section 4). We conclude by highlighting the major findings (Section 5).

\section{Study area}

Zhangye City, a prefecture-level city of Gansu province in northwestern China, is located in the middle reaches of the Heihe River and the hinterland of the Hexi Corridor (Fig. 1). Zhangye City is the choke point of the new bridge connecting Asia and Europe, and has thus become one of the preferential development areas of the national western development strategic plan. Flat topography, fertile soil, and sufficient sunshine hours (up to $3000 \mathrm{~h}$ per year), together with primary irrigation by the Heihe River, have transformed Zhangye City into one of China's 12 key national commercial grain bases. The annual precipitation in Zhangye City is only $198 \mathrm{~mm}$ as it is located within the arid continental climate zone. The average annual temperature is around $6{ }^{\circ} \mathrm{C}$, and the hottest and coldest months are July and January, respectively.

Zhangye City covers an area of $40,874 \mathrm{~km}^{2}$ and has a total population of over 1.3 million (2013), 36\% of whom are urban dwellers. There are six counties or districts, namely, Ganzhou district, Linze county, Shandan county, Minyue county, Gaotai county, and Sunan minority autonomous county. The total GDP in Zhangye City reached 336.86 billion Chinese Yuan (approximate 55.04 billion
US Dollars) in 2013 and increased by 11.8\% compared with 2012. Zhangye City has a balanced industrial structure, with a ratio of primary:secondary:tertiary industry of 1:1.29:1.33 in 2013 (Deng et al., 2014).

Expanding agriculture and rapid economic development result in the excessive use of water resources. In 2007, both the annual available water resources and the actual annual water utilizations for Zhangye City were 2.36 billion cubic meters, of which 1.96 billion cubic meters were from surface water and the reminder was from groundwater (Wu et al., 2014). The majority (99\%) of water usage is for socio-economic purposes, and of this amount, $95 \%$ is used for agriculture. Ecological and environmental water demands have not been able to be accommodated in this socio-economicdominant system. As a result, the city faces an environmental-economic dilemma through increasing dependency on the scarce water resources and increasing environment degradation (Cheng et al., 2014). Consequently, there is an imperative to alleviate water stress and promote water-use efficiency in this case study area.

\section{Data and methodology}

\subsection{General procedure used in this study}

Since it was formulated in the early twenty-first century, the WPI has been successfully applied to make both international comparisons (Lawrence et al., 2003) and numerous case studies at the local level (Sullivan et al., 2003; Zhang et al., 2012). Here, we use the conventional composite index approach and matrix (quadrant) approach (Sullivan, 2002) to generate the spatio-temporal pattern, typologies, and trajectories of water stress in the study area (Fig. 2). The primary step is to select suitable variables to represent each component (Section 3.2), following which we calculate the WPI and use different graphical devices to illustrate the spatiotemporal patterns, typologies, and trajectories of water stress for the study area.

\subsection{Water stress indicators}

Following the conceptual framework of the WPI (Sullivan, 2002), measures of water availability, access to water, the capacity for sustaining access, water use, the environmental factors that impact on water quality, and the ecology that water sustains all need to be considered to provide a multi-dimensional picture of the water stress situation (Fig. 2). Water stress needs to be quantified in a universally accepted way yet at the same time highlight local characteristics. Therefore, it is possible to adapt the WPI according to individual case study areas to ensure that it is responsive to specific socio-economic and physical situations. Therefore, in this study we adapt the Water Poverty Index as representing a location-specific WPI for the case study area of Zhangye City.

Moreover, it is desirable to reduce as much as possible the correlation among components and separate sub-indices in order to add more information to this index. It is also necessary to take data availability into consideration. Consequently, the indicators we used to represent the components of Resources, Access, Capacity, Use, and Environment in this case study are listed in Table 1 and the statistics of these variables for Zhangye City for 2005-2011 are presented in Table 2.

"Resources" refers to the total available water and here we use as a proxy the total amount of domestic, agricultural, and industrial water usage plus precipitation. "Access" means not only acquiring safe water for daily needs, but also water for irrigating crops and for industrial use. In Zhangye City, most water consumption is by agricultural usage; therefore, we choose the agricultural gross ratio and the percentage of the population with access to safe 


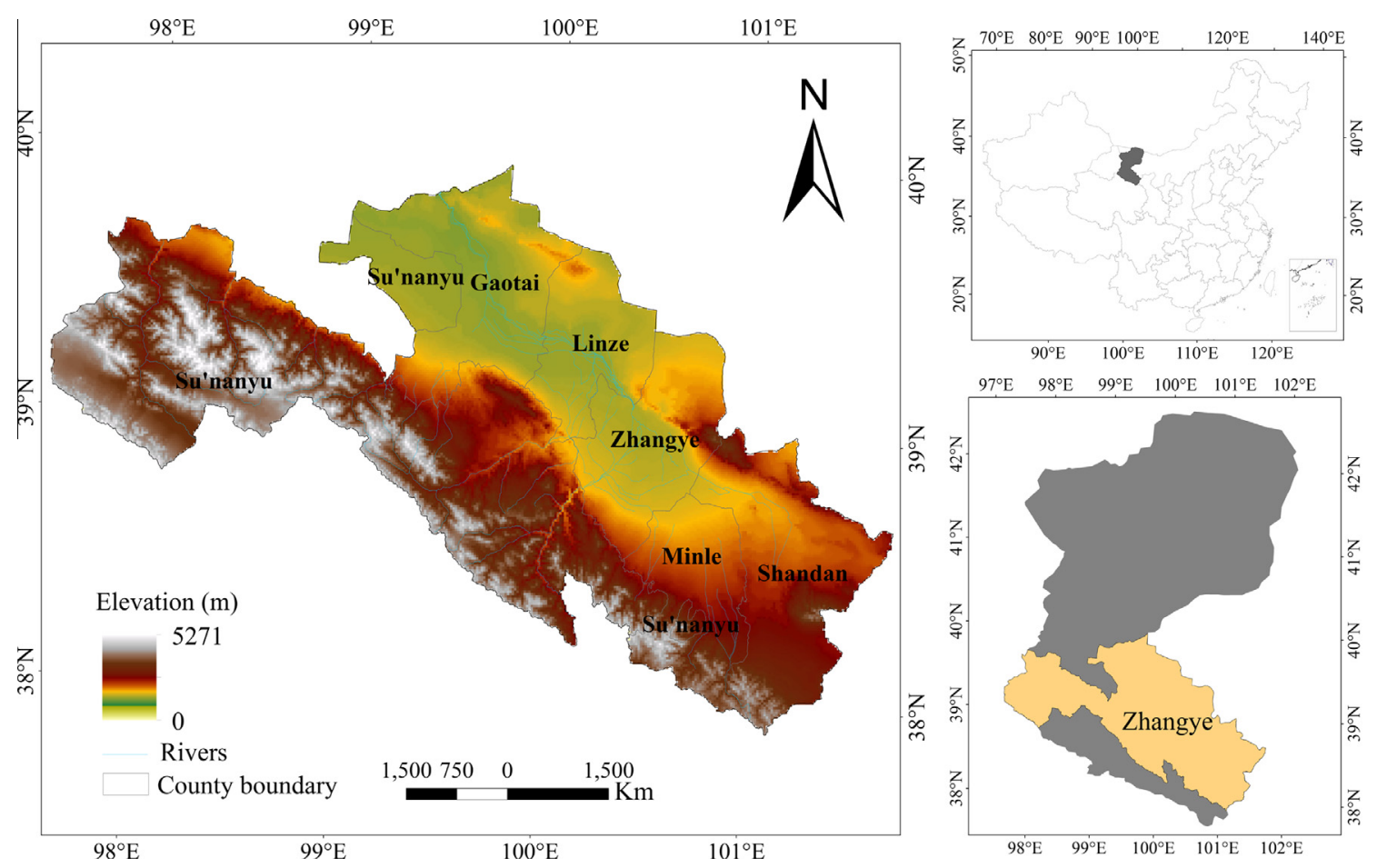

Fig. 1. Location of the study area: Zhangye City in the middle reaches of the Heihe River Basin.

water as the indicators for characterizing access. "Capacity" represents the power to purchase water and the ability to manage water supply. GDP per capita and tertiary industrial ratio are used to represent the level of economic development and are selected as the indicators of capacity. "Use" comprises domestic, agricultural, and non-agricultural water usage, and therefore indicates the total amount of domestic, agricultural, and industrial water usage in a county. "Environment" is represented by a summary of the annual average normalized differential vegetation index (NDVI), bare land area percentage, and the annual ammonia nitrogen discharge, which are indicators that measure water quality and the ecology that water sustains.

\subsection{Calculation procedure}

Each indicator is standardized to a range of $0-100$ (Equation 1), and each component is the average of its indicators with equal weights (Equation 2, see Fig. 3). The WPI for a particular location is calculated as the average of five components, namely Resources $(\mathrm{R})$, Access (A), Capacity (C), Use (U), and Environment (E), with equal weights (Equation 3 ). The values of the components and of the resulting WPI thus lie between 0 and 100 . The lowest value $(\mathrm{WPI}=0)$ represents a situation of the most severe water stress, and the highest value (WPI $=100$ ) represents the best situation where there is the lowest risk of facing water scarcity and stress.

The sub-components are categorized into positive and negative indicators. For positive indicators, the higher the original value of a factor then the less severe is the water stress and there is a better water management situation. For negative indicators, the lower the original value of a factor then the higher level of water poverty. In this study, the agricultural gross ratio in the Capacity component, the domestic, industrial, and agricultural water use in the Use component, and the bare land area percentage and ammonia nitrogen discharge in the Environment component are regarded as negative factors. All the other indicators are treated as positive. Following Heidecke's approach (Heidecke, 2006), 5\% is added to the maximum values and deducted from the lowest values during standardization to avoid the values of 0 and 100 .

\section{Results and discussion}

In this section, we analyze and interpret the five components of the WPI, together with the spatio-temporal patterns, typologies, and trajectories of the WPI at the county level. The results for the WPI as presented here suggest directions for current and future policy making, and also allow us to discuss the measurement and adaptation of the WPI.

\subsection{Spatio-temporal pattern of water stress}

The longer the bars in Fig. 4, the higher are the values of the WPI, and also the less severe the water stress situation for a particular county. The highest value of the WPI is double the lowest value. The patterns shown in Fig. 4 demonstrate the distinct spatial variation in water scarcity and stress, even for small regions (such as parts of the water basin) at the local level, here with respect to counties.

The average WPI for the six counties/districts showed no real change for the period 2005-2011 (dashed line, Fig. 5f). The WPI for each county (except Shandan county) decreased from 2010 to 2011. Over the entire study period, the WPI for three counties (Shandan, Gaotai, and Linze counties) increased, whereas it decreased for Ganzhou, Minyue, and Sunan counties, indicating that water scarcity and stress have become more severe over time in these three latter counties of Zhangye City. It is clear from Fig. $5 f$ that the data for a relatively long time series (here, 2005-2011) are more reliable for identifying and explaining the dynamics of water scarcity and stress than are short-term (snapshot) data.

There are significant variations in the values calculated for the components of Resources, Access, Capacity, and Use for the case study counties/districts. Nevertheless, no matter which county is considered, the Environment component is relatively static over 


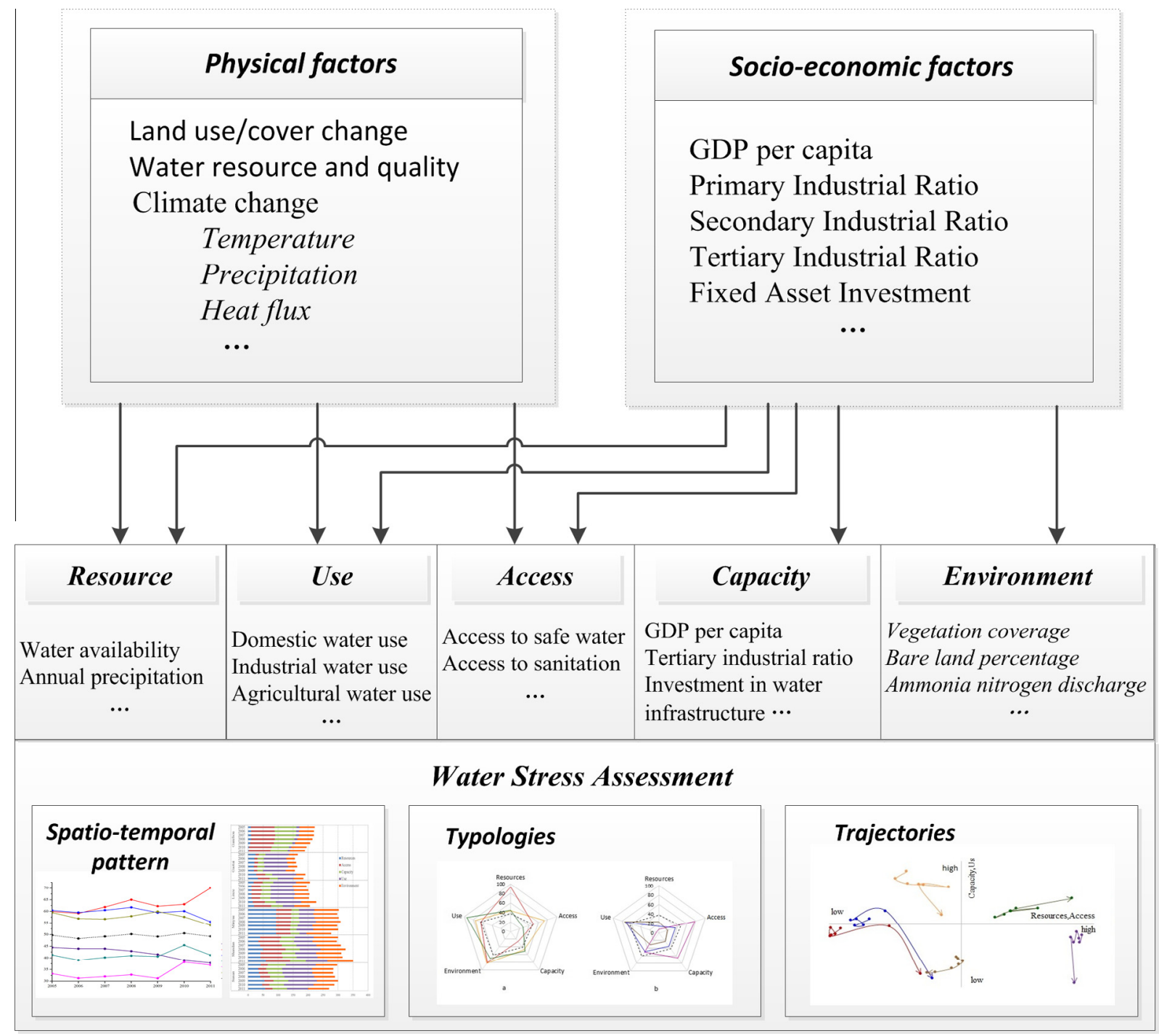

Fig. 2. General workflow of this study.

Table 1

List of indicators used in the calculation of the WPI.

\begin{tabular}{|c|c|}
\hline Component/Indicator & Description \\
\hline $\begin{array}{l}\text { Resources } \\
\text { Total water usage per capita } \\
\text { Precipitation }\end{array}$ & $\begin{array}{l}\text { Total annual amount of domestic, agricultural, and industrial water usage }\left(\mathrm{m}^{3} / \text { person } \cdot \text { year }\right. \\
\text { Annual precipitation in a county }(\mathrm{mm})\end{array}$ \\
\hline $\begin{array}{l}\text { Access } \\
\text { Percentage of the population with access to safe water } \\
\text { Agricultural gross ratio }\end{array}$ & $\begin{array}{l}\frac{\text { number of households with access to safe water (in a county) }}{\text { total number of households (in a county) }} \\
\text { Agricultural gross population as a percentage of total population in a county (\%) }\end{array}$ \\
\hline $\begin{array}{l}\text { Capacity } \\
\text { GDP per capita } \\
\text { Tertiary industrial ratio }\end{array}$ & $\begin{array}{l}\text { Per capita GDP of a county (Chinese Yuan) } \\
\text { Tertiary industrial output value as a percentage of total GDP in a county (\%) }\end{array}$ \\
\hline $\begin{array}{l}\text { Use } \\
\text { Domestic water usage } \\
\text { Industrial water usage } \\
\text { Agricultural water usage }\end{array}$ & $\begin{array}{l}\text { Total amount of domestic water usage in a county }\left(\mathrm{m}^{3}\right) \\
\text { Total amount of industrial water usage in a county }\left(\mathrm{m}^{3}\right) \\
\text { Total amount of agricultural water usage in a county }\left(\mathrm{m}^{3}\right)\end{array}$ \\
\hline $\begin{array}{l}\text { Environment } \\
\text { NDVI } \\
\text { Bare land area percentage } \\
\text { Ammonia nitrogen discharge }\end{array}$ & $\begin{array}{l}\text { Summary of the annual average normalized differential vegetation index in a county } \\
\text { Bare land area as a percentage of the total land area in a county (\%) } \\
\text { Annual discharge amount of ammonia nitrogen in a county (ton) }\end{array}$ \\
\hline
\end{tabular}

the time frame used (Fig. 5e). Because we treat the Use component as a negative one, the declines in the values of Use represent an increase in the total amount of water used. In 2011, four out of the six counties dramatically exploited water resources (Fig. 5d). During 2005-2010, the three indicators of Use remained stable, which indicates that the ranks of the total amount of domestic, 
Table 2

Statistics of indicators used in calculating the water stress index (WPI).

\begin{tabular}{|c|c|c|c|c|}
\hline Indicators & Mean & Min & Max & SD \\
\hline Resources & 37.67 & 2.14 & 93.65 & 29.15 \\
\hline Total water usage per capita $\left(\mathrm{m}^{3} /\right.$ person $\cdot$ year $)$ & 1981.17 & 819.52 & 3225.64 & 607.78 \\
\hline Precipitation (mm) & 253.46 & 79.30 & 702.00 & 133.87 \\
\hline Access & 46.91 & 9.86 & 81.44 & 23.57 \\
\hline Percentage of the population with access to safe water (\%) & 77.24 & 38.15 & 99.45 & 20.11 \\
\hline Agricultural gross ratio (\%) & 38.18 & 24.40 & 48.07 & 7.74 \\
\hline Capacity & 35.52 & 13.52 & 80.28 & 20.62 \\
\hline GDP per capita ( $10^{3}$ Chinese Yuan) & 15.78 & 5.21 & 57.38 & 9.62 \\
\hline Tertiary industrial ratio (\%) & 30.08 & 17.60 & 41.50 & 6.94 \\
\hline Use & 64.26 & 4.96 & 99.79 & 31.48 \\
\hline Domestic water use $\left(10^{6} \mathrm{~m}^{3}\right)$ & 9.76 & 0.83 & 27.44 & 7.28 \\
\hline Industrial water use $\left(10^{6} \mathrm{~m}^{3}\right)$ & 10.45 & 0.81 & 38.23 & 7.48 \\
\hline Agricultural water use $\left(10^{6} \mathrm{~m}^{3}\right)$ & 3.42 & 0.47 & 10.09 & 2.53 \\
\hline Environment & 51.25 & 29.32 & 63.51 & 10.40 \\
\hline NDVI & 15.79 & 8.89 & 22.89 & 4.31 \\
\hline Bare land area percentage (\%) & 30.07 & 5.20 & 72.39 & 22.20 \\
\hline Ammonia nitrogen discharge (ton) & 179.18 & 19.87 & 645.76 & 123.20 \\
\hline
\end{tabular}

Data sources: Statistical Bureau of Zhangye city in China (2005-2011).

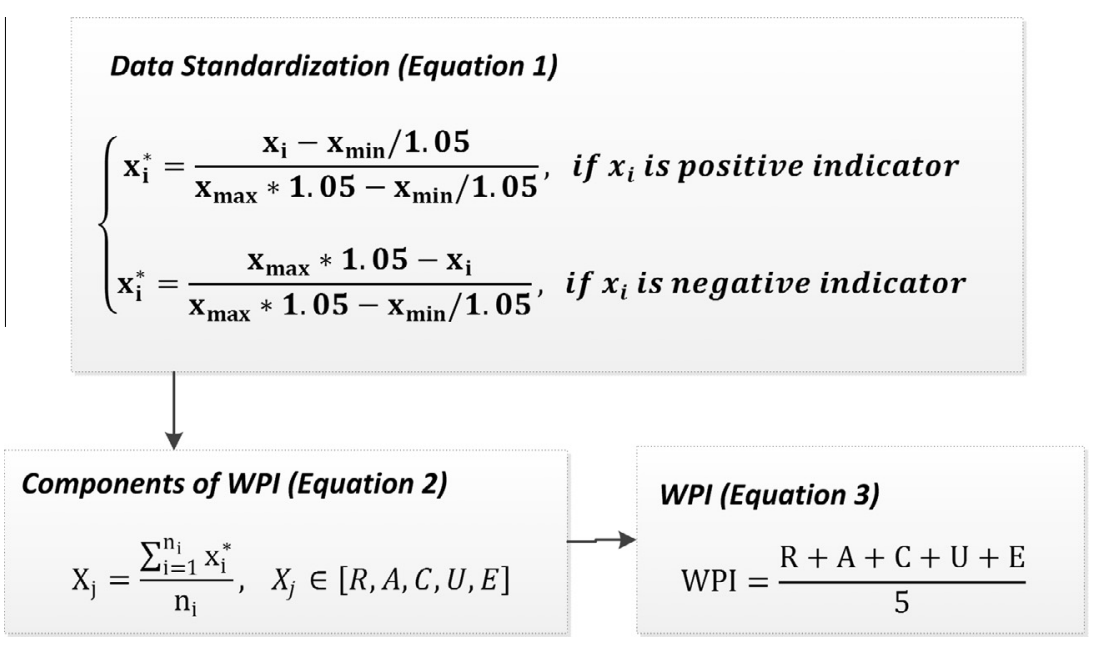

Fig. 3. Procedure for calculating the Water Poverty Index.

industrial, and agricultural water usage for each county were essentially constant. Represented by water usage in each sector, the indicators of Use also show that industrial structures for these counties had no obvious changes, and thus had no contribution to the WPI over the period 2005-2011. During the study period, most of the counties improved their capacities, with the exception of Ganzhou district, although the net value of Capacity for Ganzhou district is still the highest of the case study counties (Fig. 5c). Although the total GDP per capita of Ganzhou district continued to rise during 2005-2011, the standardized GDP per capita declined because the differential in the GDP per capita between Ganzhou district and the other counties became lower over time. In other words, economic development in other counties quickened pace to catch up with that of Ganzhou district. Access to water was either enhanced or slightly weakened over time for the six counties (Fig. 5b).

Shandan county shows relatively high scores on multiple components, and has the highest WPI (Fig. 5f), reflecting its progressive policies on water access and management. Minyue county, largely as a result of having the highest water availability (Fig. 5a), has the second-highest WPI value for Zhangye City. Sunan county is the third and final county that shows a higher WPI than the average value. The severity of water stress in Sunan and Minyue counties, and in Linze and Gaotai counties, is similar because the change in WPI and the dynamic patterns in these two pairs of counties over time are similar. Ganzhou district, which contains the single largest percentage of the total population of Zhangye City, has been facing increasing pressure on water scarcity and stress, as shown by the steady decline in its WPI (Fig. 5f).

\subsection{Typologies and trajectories of water stress}

Radar maps have been widely used in previous assessments of water poverty and stress (Sullivan and Meigh, 2007; Sullivan et al., 2003; Zhang et al., 2012; Zheng et al., 2012). Beyond interpreting the radar maps as a way of describing the components of the WPI, we can distinguish the diverse types of water stress from the radar map pentagrams that represent water situations in these case study counties (Fig. 6a and b). The shape of the pentagram for Shandan county is similar to (but with higher values than) the average. The greater the enclosed pentagram area for a county, the better the situation for that county regarding water access and management. Three of the six counties are better (Fig. 6a) and three worse (Fig. 6b) compared with the average level. Moreover, the pentagram shapes show considerable variation, which indicates that all these counties faced their own challenges and opportunities in the context of water scarcity and stress. Similar to the concept of urbanization typology, the counties sharing 


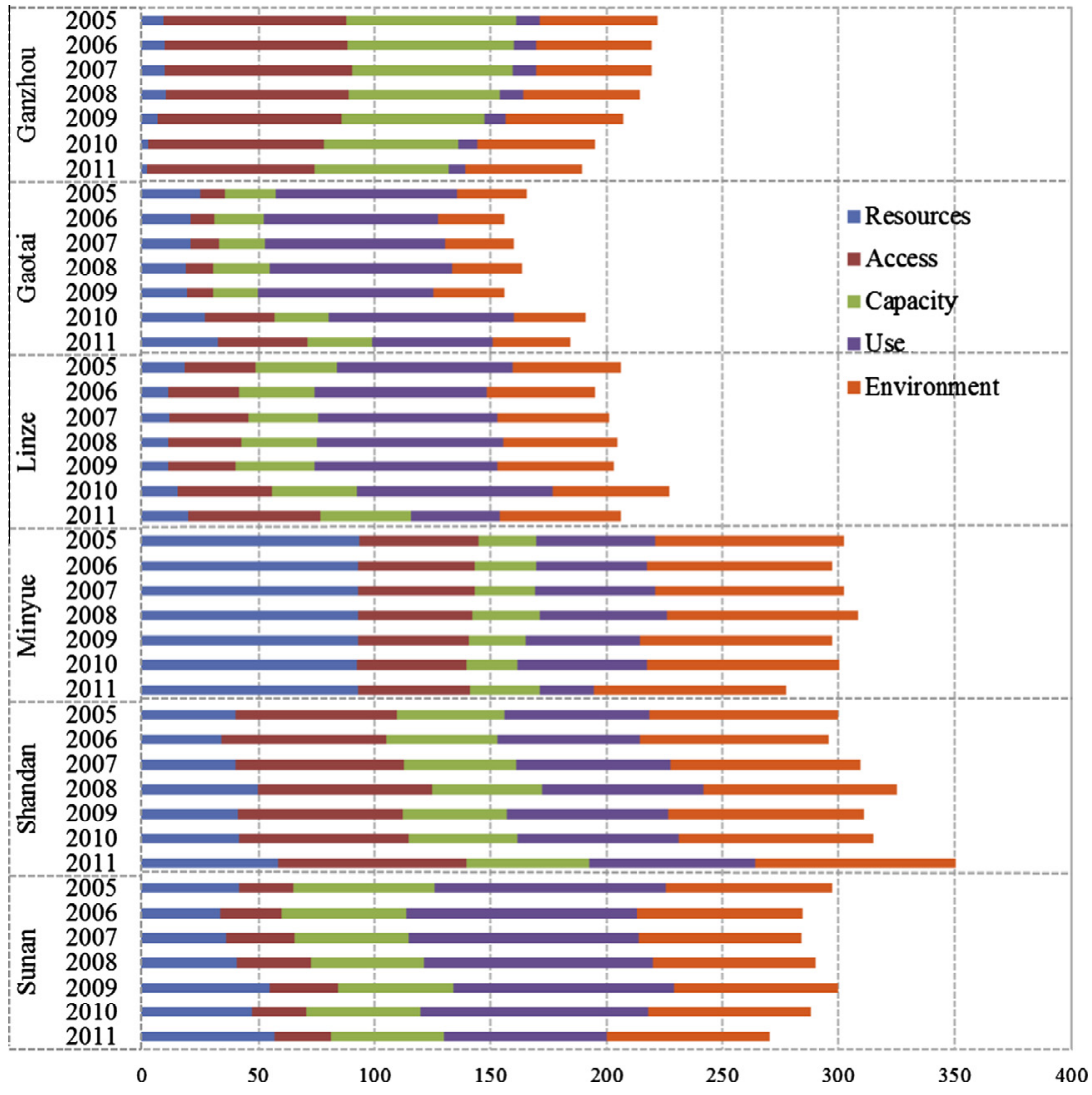

Fig. 4. Water stress index and its components for the six studied counties of Zhangye City.

similar typologies might face similar problems and the undergoing processes or strategies in one county might provide useful referential information and guidance for decision-making in other counties with similar typologies (Zhang and Seto, 2013). Nevertheless, in some cases the different typologies might be attributed to different underlying causes and processes of water access and management. Water stress typologies based on the components (Resources, Use, Access, Capacity, and Environment) provide a comprehensive understanding of water scarcity and stress.

Another important contribution of the radar maps is that they can distinctly illustrate where progress needs to be prioritized for alleviating water scarcity and stress in the particular local situation (Fig. 6a and b). For example, for Minyue country, improving accessibility to water and increasing the capacity are more important than taking other actions to alleviate water stress. In contrast, given the more limited amount of available water, achievement of a balanced water use structure makes more sense for Ganzhou district.

Following Sullivan (2001a,b), we omitted the environment component and integrated the other four components into a two-dimensional matrix. The relative positions in this two-dimensional space represent the counties with different levels of water Availability (Resources) and Access ( $x$-axis), and of Capacity and Use ( $y$-axis). Previous water stress assessments presented the static locations of the study units in four quadrants (Sullivan, 2002). However, importantly, time series of WPIs are more powerful than a snapshot of the index for a single year. Using time series of WPIs and treating them as continuous curves allows the trajectories of water stress changes to be tracked, which we demonstrate below for the counties of the study area.

In the graphical device used for presenting the trajectories of water stress (Fig. 7), the origin and terminations of the $x$ - and $y$-axes represent the minimum and maximum values of the mean values of Resources and Access and of Capacity and Use, respectively. The arrows show the temporal trajectory of each county through the dimensions from 2005 to 2011 (Fig. 7). A trajectory of points from the lower-left (low-low or LL) quadrant to the upper-right (high-high or $\mathrm{HH}$ ) quadrant would indicate a substantial improvement in both water Availability-Access and CapacityUse, and can be defined as progression. In this case study, only the curve for Shandan county is located in the HH quadrant, and the trend heads slightly upwards and to the right, indicating an improving water situation. The curves for Gaotai, Linze, and Sunan counties all trend downwards and to the right, which means an increase in Availability and Access but a decrease in Capacity and Use. Minyue's curve trends downwards and slightly left in the HL quadrant, even though the original value of Availability and Access for this county is high. Ganzhou's curve trends downwards and left in the LL quadrant, showing regression over time in both dimensions.

\subsection{Discussion of methodology and future research}

We are able to make several points regarding the methodology used and avenues for further research. First, the values of the WPI, together with its components and subcomponents, are "indicators", and not precise measures. The WPI produces values that allow comparisons and rankings to be made in the provision, access, and management of water resources at specific levels (such as international, national, and local levels); thus the index provides a means to make relative judgments for the level or area under consideration, but the absolute values themselves are not meaningful. The purpose of generating the WPI is to make comparisons 
(a) Resources

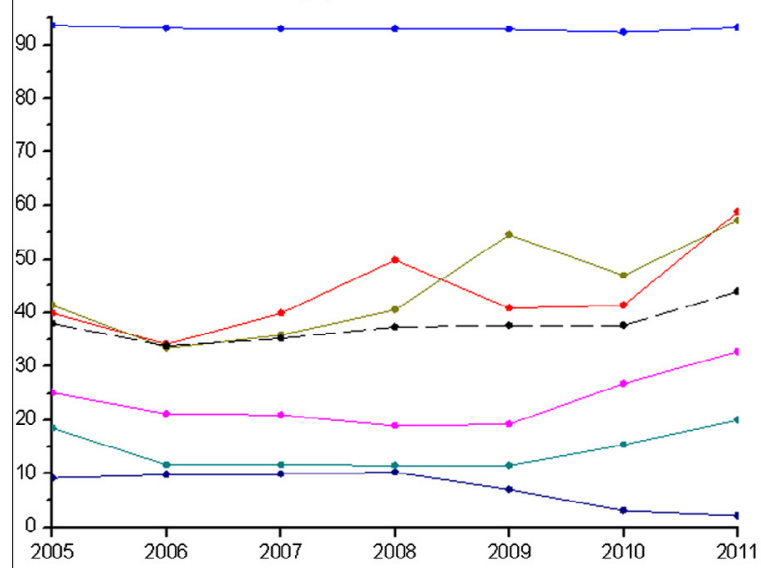

(c) Capacity

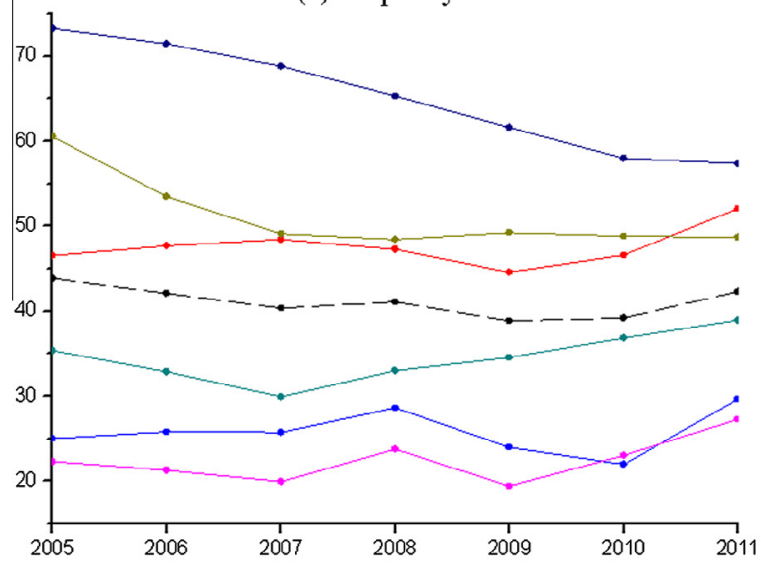

(e) Environment

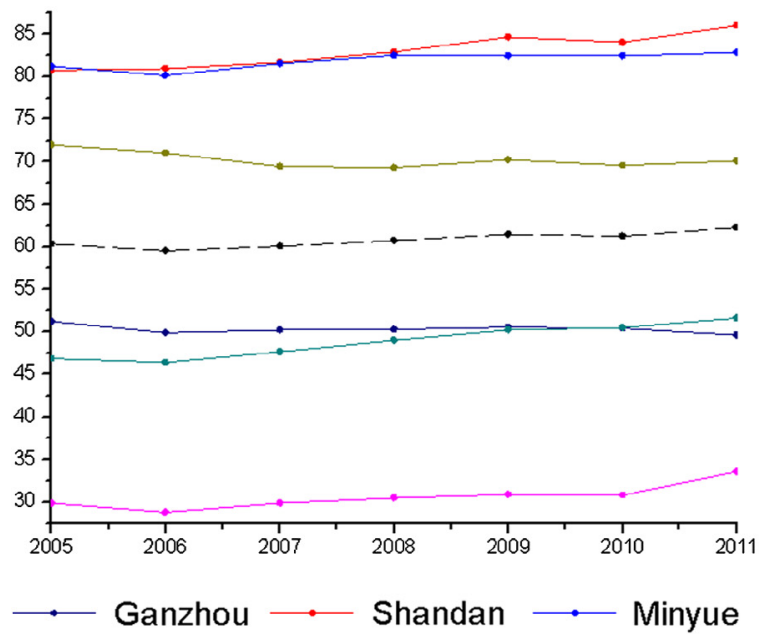

(b) Access

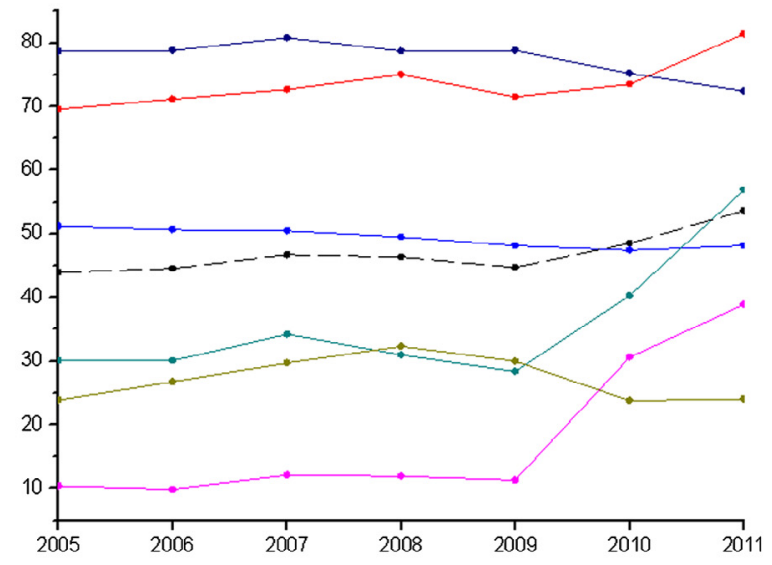

(d) Use

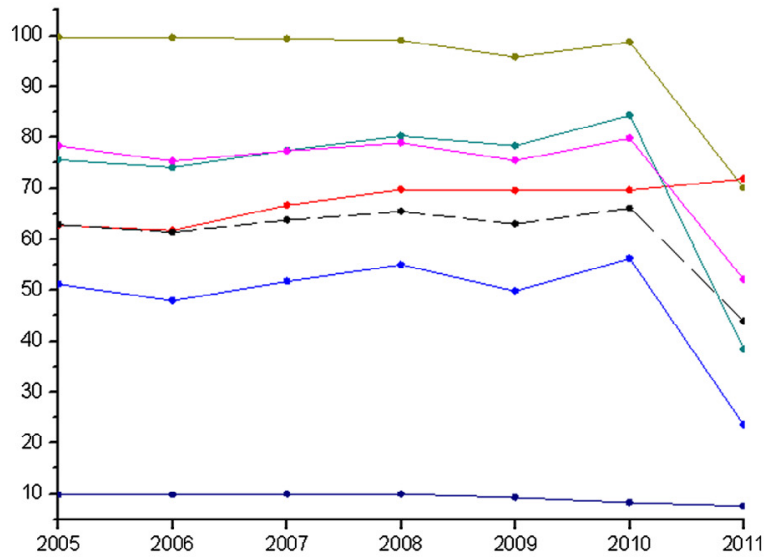

(f) Water Poverty Index

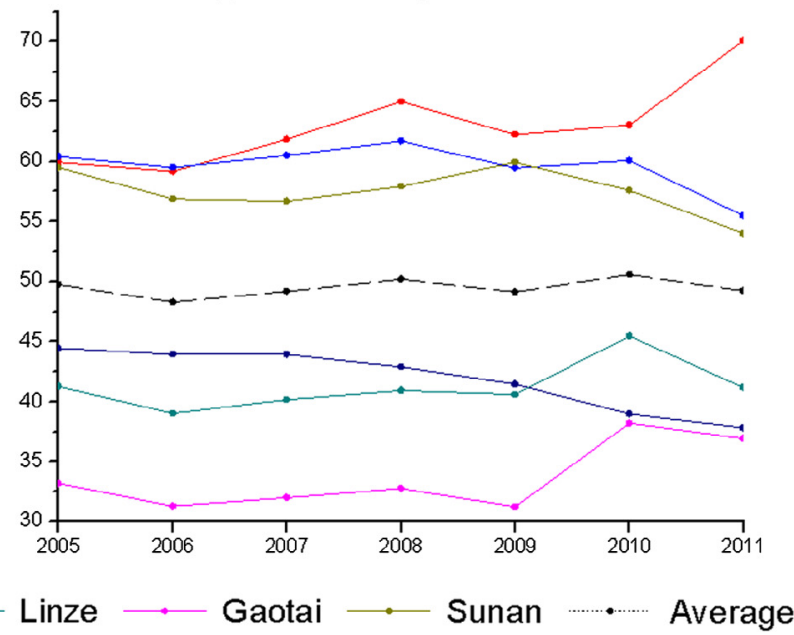

Fig. 5. Dynamics of the WPI and its components for the six studied counties of Zhangye City.

between regions and to inform decision-makers, rather than provide a complex statistical assessment.

Second, the WPI is location specific and question oriented in nature, and we can adapt this index by including more available data, such as the amount of investment in water infrastructure, or by assigning different weights to the five components and various sub-components. In this study, we weighted the five components equally given the absence of information suggesting otherwise. Some researchers have argued that less weight should be given to Resources and more to Use, Access, and Environment to highlight the importance of management rather than natural water distribution (Wada, 2010; Wu and Li, 2013). However, how such differential weightings should be determined and how to maximize the information that each component and 


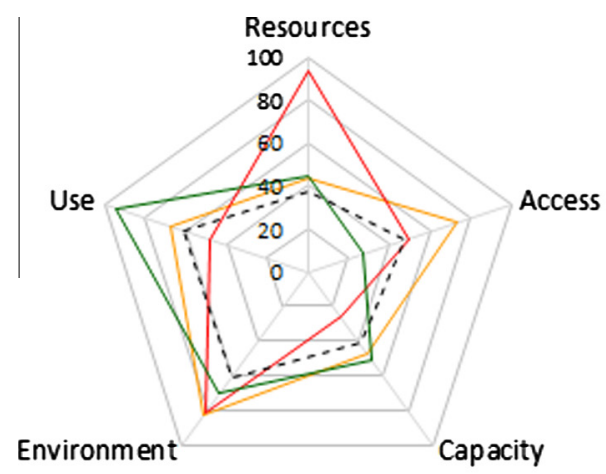

a

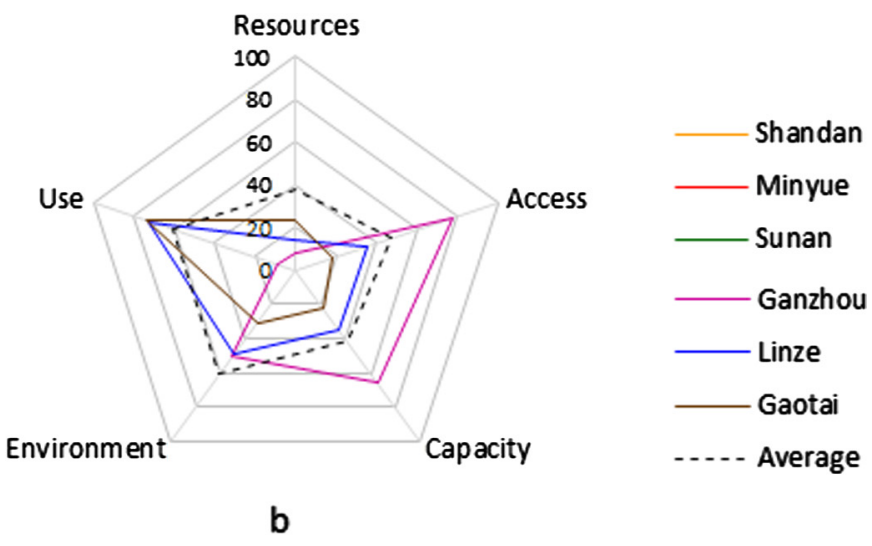

Fig. 6. Water stress typology for the six studied counties of Zhangye City.

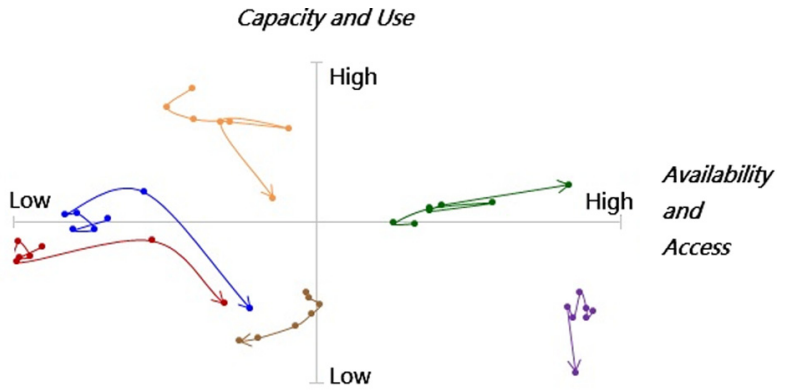

$\rightarrow$ Ganzhou $\rightarrow$ Shandan $\rightarrow$ Minyue $\rightarrow$ Linze $\rightarrow$ Gaotai $\rightarrow$ Sunan

Fig. 7. Trajectories of water stress for the six studied counties of Zhangye City.

sub-component can provide are challenging problems and need to be addressed in future studies. In our case study, we followed the successful experience of the Human Development Index (HDI) by assigning equal weights to the components and using unweighted averages of subcomponents (Klugman, 2010).

Third, it has been argued that the WPI essentially provides a measure of water availability and access that is adjusted by socio-economic and environmental factors and therefore that it attempts to combine "apples" with "pears" (Lawrence et al., 2003). It is a tough challenge to integrate both socio-economic factors and bio-geophysical elements into one single index because of their variant spatial and temporal scales (Srinivasan et al., 2013). Bio-geophysical data from monitoring are usually based on hydrological stations and can be captured at fine spatial and temporal resolutions. In contrast, socio-economic data are derived mainly from censuses at county, prefecture, provincial, or national levels at annual intervals, or from investigations at the household level. Therefore, data upscaling or downscaling is necessary to match data from multiple sources. By geo-referencing and linking the various WPI indicators, water stress can be assessed at different scales, which has been shown to be imperative because patterns of water stress and scarcity vary greatly across these various scales (Perveen and James, 2009, 2011). In the present study, we calculated the WPI at the county scale because these administrative units are powerful in formulating land and water use policies in China (Zhang et al., 2014). Analysis of the spatio-temporal patterns, typologies, and trajectories of water stress for counties as performed here will help water managers at both local and national government levels to identify policy priorities and implications. Moreover, climate change has a significant impact on water stress dynamics (Griffin et al., 2013), and water availability in both dry and wet seasons is another distinct problem (Sullivan and Meigh,
2007; Sullivan et al., 2003; Wada, 2010). Consequently, we should take climate change and seasonal variation into consideration and facilitate the multi-scale integration of climate change, hydrologic, water resource, and socio-economic data. Multi-scale assessments will help provide a better understanding of water scarcity and stress, which in turn will improve water use policy in China.

Fourth, the idea behind generating the WPI follows the mainstream approach in the last two decades for evaluating the status of nature and society using composite indexes, such as the Human Development Index (HDI) at the country scale (Klugman, 2010), the City Development Index (CDI) at the city level (UN-Habitat, 2007), and the water resource vulnerability indicator (Hamouda et al., 2009). The condensed indices are very useful for focusing attention on and simplifying the problem, and they are also better able to draw public attention and to influence policy makers' decisions than are long lists of many factors. As a result, the indices have considerable political appeal despite their poorer statistical value compared with precise measures.

Last but not least, although the WPI has attracted some criticism (Lawrence et al., 2003), one prominent advantage of the WPI we wish to highlight is that the conceptual framework and pilot projects of the WPI were developed as a consensus of opinion from a wide range of physical and social scientists, water practitioners, researchers, water users, agency personnel, and other stakeholders to ensure that all the relevant issues were included in the index. The process of "co-design" and "co-development" has also been proposed and recommended by Future Earth (http:// www.icsu.org/future-earth/), which is a "new 10-year international research initiative that will develop the knowledge for responding effectively to the risks and opportunities of global environmental change and for supporting transformation towards global sustainability in the coming decades".

\section{Conclusion}

Water scarcity and stress have attracted increasing attention as water has become to be regarded as one of the most critical resources in the sustainable development of the world. The Water Poverty Index (WPI), an interdisciplinary but straightforward measure that considers water availability from bio-geophysical aspects and from people's capacity to access water from a socio-economic perspective, has been successfully applied in various case studies at national, regional, and local levels around the world. However, the general assessment of water stress at a macro level over only a short time period or snapshot will limit the understanding of the geographic variations in and dynamics of water stress, which in turn will mislead decision-makers and may result in the implementation of improper strategies. To date, the typologies 
and trajectories of water stress have been underexplored. Here, to fill this gap in knowledge, and using an adapted WPI, we examined the temporal trends and spatial patterns of water stress, investigated the underlying components and indicators that affect water stress, and explored the trajectories and typologies of water stress, on which basis we have been able to provide policy priorities for six specific counties of Zhangye City.

The results of our study indicate that water scarcity and stress have become more severe for most of the counties in Zhangye City over the period 2005-2011. There is clear spatial variation in water scarcity and stress between the different counties. Specifically, Shandan county scored relatively highly in the WPI and across multiple components, reflecting its progressive policies on access and management and its good water governance. In contrast, Ganzhou district, which contains the largest single percentage of the total population of Zhangye City, has faced increasing water scarcity and stress, and is regarded as having poor water governance. An analysis of water stress typologies using radar maps shows that each county had a distinct radar map pentagram shape, which indicates that each county faced its own particular challenges and opportunities in the context of water scarcity and stress. In addition, the trajectories map reveals that none of the counties has substantially improved both water access and management, a finding that should attract the attention of decisionmakers. In short, the WPI, serving as a simple, transparent, and holistic tool, provides a better understanding of the complexities of water scarcity and stress by integrating physical, socio-economic, and environmental factors. This is particularly the case when changes in the index can be assessed over a reasonable period of time and when the trajectories of the index and its components can be tracked and its typologies identified. The WPI appeals to decision-makers and should also serve to empower the public to participate in practicing effective and efficient water management through determining and justifying policy priorities.

\section{Conflict of interest}

The authors declare no conflict of interest.

\section{Acknowledgments}

This research was financially supported by the major research plan of the National Natural Science Foundation of China (Grant No. 91325302) and by the National Natural Science Funds of China for Distinguished Young Scholars (Grant No. 71225005).

\section{References}

Alcamo, J., Döll, P., Kaspar, F., Siebert, S., 1997. Global Change and Global Scenarios of Water Use and Availability: An Application of WaterGAP 1.0. Center for Environmental Systems Research (CESR), University of Kassel, Germany, Germany.

Cheng, G., Li, X., Zhao, W., Xu, Z., Xiao, S., Xiao, H., 2014. Integrated study of the water-ecosystem-economy in the Heihe River Basin. Natl. Sci. Rev. 1, 413-428.
Deng, X., Zhao, C., 2014. Identification of water scarcity and providing solutions for adapting to climate changes in the Heihe River Basin of China. Advances in Meteorology (in press).

Deng, X., Zhang, F., Wang, Z., Li, X., Zhang, T., 2014. An extended input output table compiled for analyzing water demand and consumption at county level in China. Sustainability 6, 3301-3320.

Falkenmark, M., Whdstrand, C., 1992. Population and water resources: a delicate balance. Popul. Bull. 47, 1-36.

Feitelson, E., Chenoweth, J., 2002. Water poverty: towards a meaningful indicator. Water Policy 4, 263-281.

Griffin, M.T., Montz, B.E., Arrigo, J.S., 2013. Evaluating climate change induced water stress: a case study of the Lower Cape Fear basin, NC. Appl. Geogr. 40, 115-128.

Hamouda, M.A., Nour El-Din, M.M., Moursy, F.I., 2009. Vulnerability assessment of water resources systems in the eastern Nile basin. Water Resour. Manage 23 2697-2725.

Heidecke, C., 2006. Development and Evaluation of a Regional Water Poverty Index for Benin. International Food Policy Research Institute.

Klugman, J., 2010. The Real Wealth of Nations: Pathways to Human Development, Human Development Report. United Nations Development Programme (UNDP).

Lawrence, P., Meigh, J., Sullivan, C., 2003. The Water Poverty Index: An International Comparison. Keele Economics Research Papers 2003/18.

Perveen, S., James, L.A., 2009. Multiscale effects on spatial variability metrics in global water resources data. Water Resour. Manage 24, 1903-1924.

Perveen, S., James, L.A., 2011. Scale invariance of water stress and scarcity indicators: facilitating cross-scale comparisons of water resources vulnerability. Appl. Geogr. 31, 321-328.

Smakhtin, V., Revenga, C., Döll, P., 2004. Taking into Account Environmental Water Requirements in Global-scale Water Resources Assessments, Comprehensive Assessment Research Report 2, Colombo, Sri Lanka.

Srinivasan, V., Seto, K.C., Emerson, R., Gorelick, S.M., 2013. The impact of urbanization on water vulnerability: a coupled human-environment system approach for Chennai, India. Global Environ. Change 23, 229-239.

Statistics Bureau of Zhangye City, 2005-2011. Statistical Yearbook for Zhangye City.

Sullivan, C., 2001a. The potential for calculating a meaningful water poverty index. Water Int. 26, 471-480.

Sullivan, C., 2001b. Redefining the Water Poverty Index - A Commentary.

Sullivan, C., 2002. Calculating a water poverty index. World Dev. 30, 1195-1210.

Sullivan, C., Meigh, J., 2007. Integration of the biophysical and social sciences using an indicator approach: the example of the climate vulnerability index. Water Res. Manage. 21, 111-128.

Sullivan, C., Meigh, J., Giacomello, A.M., Fediw, T., Lawrence, L., Samad, M., Mlote, S. Hutton, C., Allan, J.A., Schulze, R.E., Dlamini, D.J.M., Cosgrove, W., Priscoli, J.D., Gleick, P., Smout, I., Cobbing, J., Calow, R., Hunt, C., Hussain, A., Acreman, M.C. King, J., Malomo, S., Tate, E.L., O’Regan, D., Milner, S., Stey1, I., 2003. The water poverty index: development and application at the community scale. Natl. Res. Forum 27, 10.

UN-Habitat, 2007. Global Urban Indicators Database Version 2. United Nations Publication, Narobi, Kenya.

Vörösmarty, C.J., Green, P., Salisbury, J., Lammers, R.B., 2000. Global water resources vulnerability from climate change and population growth. Science 289, 284 289.

Wada, Y., 2010. Water Stress over the Year: Quantitative Analysis of Seasonality and Severity on a Global Scale. University of Utrecht, The Netherland.

Wu, R., Li, Y., 2013. Application of fuzzy assessment model of water resources security based on AHP. J. Water Res. Water Eng. (in Chinese) 24, 139-144.

Wu, F., Zhan, J., Wang, Z., Zhang, Q., 2014. Streamflow variation due to glacier melting and climate change in upstream Heihe River Basin, Northwest China. J. Phys. Chem. Earth. http://dx.doi.org/10.1016/j.pce.2014.08.002.

Zhang, Q., Seto, K.C., 2013. Can night-time light data identify typologies of urbanization a global assessment of successes and failures. Remote Sens. 5 3476-3494.

Zhang, R., Duan, Z., Tan, M., 2012. The assessment of water stress with the water poverty index in the Shiyang River Basin in China. Environ. Earth Sci. 67, 2155 2160.

Zhang, Q., Wallace, J., Seto, K.C., Deng, X., 2014. Central versus local states: which matters more in affecting China's urban growth? Land Use Policy 38, 487-496.

Zheng, Z., Liu, J., Koeneman, P.H., Zarate, E., Hoekstra, A.Y., 2012. Assessing water footprint at river basin level a case study for the Heihe River Basin in northwest China. Hydrol. Earth Syst. Sci. 16, 2771-2781. 